\title{
DSM5-eko nortasun-nahasteak ebaluatzeko tresnen itzulpena eta balidazioa. Euskal Autonomi Erkidegoan egindako ikerketa bat
}

\author{
Naiara Ozamiz Etxebarria*, Agurtzane Ortiz Jauregi, Jose Guimon \\ Euskal Herriko Unibertsitatea \\ Javier Escobar \\ Rutgers University \\ *naiara.ozamiz@ehu.eus
}

DOI: $10.1387 /$ ekaia.14518

Jasoa: 2015-05-20

Onartua: 2015-11-30

Laburpena: 2013ko maiatzaren 18an, APAk (Amerikar Psikiatria Elkartea), gaixotasun mentalen diagnostiko eta estatistikaren bosgarren eskuliburua «Diagnostic and Statistical Manual of Mental Disorders (DSM-5») publikatu zuen. Eskuliburuaren hirugarren sailean (Neurketa tresna eta eredu berriak), DSM-5eko nortasunaren eta nortasun-nahasteen lan taldeak nortasunaren psikopatologiaren ebaluazio eta diagnostikoan birformulatze esanguratsua gomendatu du.

Ikerketa honen bitartez, tresna berri horiek balidatu ditugu Euskal Herrian hartutako lagin batean. Euskal Herriak herrialde elebiduna izatearen berezitasuna dauka; horregatik nabaria da tresna hauek euskarara itzultzearen garrantzia, batez ere, euskara ama-hizkuntza duten ebaluatzaile eta gaixoentzat.

Hitz gakoak: Nortasun-nahastea, DSM-5.

\begin{abstract}
In May 18, 2013 the APA, (American Psychiatric Association), published the Diagnostic and Statistical Manual of Mental Disorders (DSM-5»). In section III of the Manual «Emergent Measures and new Models», the Personality and Personality Disorder Work Group of the DSM-5 recommended a significant reformulation of the evaluation and diagnosis of personality psychopathology. The present investigation intends to validate these new instruments in a sample of the Basque Country. Due to the fact that this region has the peculiarity of being bilingual the importance of translating the instruments into the Basque language (euskara) was recognized in order to include evaluators and patients whose mother tongue was Basque.
\end{abstract}

Keywords: Personality disorder, DSM-5. 
Naiara Ozamiz Etxebarria, Agurtzane Ortiz Jauregi, Jose Guimon

eta Javier Escobar

\section{SARRERA}

DSM (Diagnostic and Statistical Manual of Mental Disorders) APAk sortutako gaixotasun mentalen sailkapena da. Mundu guztiko ikertzaile, kliniko, konpainia farmazeutiko, osasun-aseguru konpainia eta politikoek erabiltzen dute, AEBetan batez ere.

Lehenengoa 1952an publikatu zenetik beste bost errebisio egin dira. Errebisio horietan, zenbait nahaste mental kendu edo gehitu dira, egon diren beharren arabera. Laugarren edizioa (DSM-IV), 1994. urtean sortu eta 2000. urtean errebisatu zen. Azkeneko edizioa 2013. urteko maiatzaren 18 an argitaratu zen, San Frantziskon urtero ospatzen den APAren kongresuan.

2010. urteko otsailean, DSM-5eko lan-taldeek gaixotasun mentalen birformulazioak proposatu zituzten, herrialdeka landa-ikerketak egiteko, eta birformulazio horietan sortutako irizpideak balioztatzeko. Nortasunnahasteen lan taldeak ere tresna batzuk sortu zituen irizpide berri horiek baloratzeko. Garrantzitsua da irizpide horiek herrialde eta kultura desberdinetan balioztatzea, tresnen baliozkotasuna handiagotzeko. Euskal Herriak herrialde elebiduna izatearen berezitasuna dauka. Lan honen bitartez, irizpide berri horiek Euskal Autonomia Erkidegoan bildutako lagin batean balioztatu dira. Horretarako, euskarara itzuli ziren jatorriz ingelesez zeuden tresnak, euskara ama-hizkuntza duten paziente eta ebaluatzaileentzat baliagarriak izan daitezen, eta galdeketa egin zitzaien DSM-IVan nortasun-nahastea diagnostikaturik zuten paziente euskaldun batzuei.

\section{DSM 5-ERAKO PROPOSAMEN BERRIAK ETA JUSTIFIKAZIOA}

Esan bezala, 2010. urteko otsailaren 10ean, nortasun-nahasteen birformulazio bat egin zen DSM-5eko nortasun-nahasteen atalean eta nortasunaren definizioa ere aldatu zen. Birformulazio horretan, garrantzia eman zaio nortasun-nahasteen diagnostikoa testuinguru desberdinetara egokitzeari, pertsonarteko harremanei eta banakoaren identitatearen narriadurari.

Eredu horretan, bost kategoria espezifiko desagertu ziren eta soilik bost geratu dira. Geratu diren nortasun-nahasteak nortasun-nahaste antisoziala, saiheskorra, obsesibo-konpultsiboa eta eskizotipikoa dira (Skodol et al. 2011) [1]. Bestalde, eredu kategoriala dimentsionalarekin konbinatzen da. Kategoria bakoitzak deskribapen bat dauka, eta haiek 1etik 5erako eskala batekin baloratu behar dira (Moran 2011) [2]. Pazienteak puntu-kopuru jakin bat jasotzen du nortasun-nahaste baten deskribapenera egokitzen den neurriaren arabera (ikus lehenengo taula). 
DSM5-eko nortasun-nahasteak ebaluatzeko tresnen itzulpena eta balidazioa. Euskal Autonomi Erkidegoan egindako ikerketa bat

1. taula. Nortasun-nahaste saiheskorra dimentsionalki neurtzeko modua.

\begin{tabular}{ll}
\hline & SAIHESKORRA \\
\hline 4 & Oso ona: Gaixoa eredu honen adibidea da \\
3 & Moderatuki: Gaixoak eredu honen ezaugarri nabarmenak ditu \\
2 & Baxua: Gaixoak eredu honen ezaugarri gutxi batzuk ditu \\
1 & Bat ere ez: Gaixoak ez du deskribapen honekin zerikusirik \\
\hline
\end{tabular}

Gainera, nortasunaren sei eremuren (emozio negatiboak, barnerakoitasuna, desinhibizioa, konpultsibotasuna, eskizotipia, aurkakotasuna) eta hogeita hamazazpi ezaugarriren sailkapena egiten da; hala nola, labilitate afektiboa, antsietatea, menpekotasuna, aldentzearekiko herstura, ezezkotasuna, auto-estimu txikia, lotsa, bere burua zauritzea, depresio-joera, mesfidantza, bakartze soziala, axolagabetasun soziala, intimitate-saihestea, afektibitate baxua, interes falta, inpultsibotasuna, arreta-galtzea, ausarkeria, arduragabekeria, perfekzionismoa, pertseberantzia, buru-zurruntasuna, gehiegizko ordena, arriskuen beldurra, ez-ohiko pertzepzioak, ez-ohiko sinesmenak, eszentrikotasuna, disonantzia kognitiboa, disoziazioak, manipulazioa, engainua, nartzisismoa, besteen arreta bilatzea, gogortasuna, etsaikeria, erasozko portaerak, negatibotasuna, eta haiek ere 0tik 3rako eskala batean baloratzen dira.

Pazientearen egunerokotasuneko funtzionamendu-mailei ere 0tik 4rako puntuak esleitzen zaizkie (kalterik gabe, kalte txikia, kalte neurritsua, kalte larria, muturreko kaltea). Modu horretan ere, pazientearen larritasun maila neurtzen da.

Aldaketa horiek guztiak lehenengo zirriborroan agertutakoak dira; ordutik aurrera, aldaketa asko jasan ditu DSM-5ak. Orain azaldutako birkontzeptualizazio horren antzekoa da, beraz, DSM-5aren hirugarren sailean, - hots, ikerketa bidean dauden ereduen sailean - gaur egun agertzen dena. Hauek izan dira birkontzeptualizazio berri horren arrazoi nagusiak: nortasun-nahasteen arteko gehiegizko komorbilitatea, diagnostiko berdina duten pazienteen arteko gehiegizko hetereogeneotasuna, diagnostikoan ezegonkortasuna egotea/agertzea denboran zehar, larritasun-dimentsioak erabiltzearen beharra eta espezifikaturik gabeko nortasun-nahastea gehiegi diagnostikatzea.

\section{IKERKETAREN HELBURU ETA HIPOTESIAK}

Ikerketa honen helburu nagusia DSM-5eko Nortasun-nahasteak neurtzeko tresnak euskarara itzultzea eta tresna hauen eduki aldetiko baliozkotasuna neurtzea dira. Modu horretan, nortasun-nahaste motak neurtzen di- 
tuzten tresnek eduki-baliozkotasuna izango dute eta nortasun-ezaugarriak neurtzeko proposatzen dituzten sei eremuek nahiz hogeita hamazazpi ezaugarriek argi eta garbi definituko dituzte nortasun-ezaugarriak.

Bestalde, euskarara itzulitako tresnak ulergarriak eta erabilgarriak izatea espero da, bai pazienteentzat bai ebaluatzaileentzat. Horrela, paziente eta ebaluatzaile euskaldunen arteko komunikazioa ere erraztu egingo da.

\section{METODOLOGIA}

\subsection{Datuen bilketa}

Datu bilketa Euskal Herriko zenbait erakundetan egin zen. Santurtziko San Juan de Dios ospitaleko psikiatria-esparruan, Bilbon, Indautxun eta Elkanon kokaturik dauden AMSAko (Avances Médicos, S.A.) Eguneko Zentroetan, Basurtoko Ospitale Psikiatrikoan, Gernikako Osasun Mentaleko Zentroan, Bermeoko Osasun Mentaleko Zentroan, Donostiako Bitarte droga-mendekotasun osasun-zentroan eta Irungo Bitarte droga-mendekotasun osasun-zentroan. Aukeratu ziren pazienteen ama-hizkuntza euskara zen, eta hamazortzi urtetik gorakoak izan behar zuten. Haiek nortasun-nahaste diagnostikoa zuten DSM-IVan eta modu boluntarioan parte hartu zuten ikerketan, beren zentroetako psikiatra eta psikologoen informazioa jaso ondoren. Landa-ikerketa honetan 32 pazientek hartu zuten parte.

\subsection{Tresnen itzulpenerako}

Tresna originalak euskaratzeko, «Back Translation» metodoa erabili genuen. Metodo honen bitartez, tresna originalak hizkuntza batera itzultzen ditu itzultzaile batek. Ondoren, bigarren itzultzaile batek berriro itzultzen du tresna hau jatorrizko hizkuntzara. Azkenik, hirugarren ebaluatzaile batek jatorrizko testua berriro itzulitako testuarekin konparatzen du, esanahi bera dutela egiaztatzeko. Modu honetan, kalitatezko itzulpenak lortzen dira.

\subsection{Tresnak aplikatzeko metodologia}

Tresnen aplikaziorako test-retest metodologia erabili zen. Test-retest metodologiaren bitartez, pazienteek bi aldiz erantzuten diote test berdinari, bi elkarrizketen/saioen artean denbora tarte bat utzita. Bi momentu horietan ateratako emaitzen arteko korrelazioa egiten da, eta korrelazioa altua ateratzen bada, pazienteak bi aldietan modu berdinean edo antzekoan erantzun duela esan nahi du (Campo-Arias, Herazo, 2010) [3].

Gure kasuan, metodologia hori erabiliz, elkarrizketa bat egin zen lehenengo, eta hurrengo bat hilabete bat geroago, irizpide hauen fidagarritasuna neurtzeko. 
DSM5-eko nortasun-nahasteak ebaluatzeko tresnen itzulpena eta balidazioa. Euskal Autonomi Erkidegoan egindako ikerketa bat

\subsection{Neurketa estatistikoak}

DSM-5eko lan taldearen aholkuak jarraituz, test-retest moduko kappa estatistikoak egin ziren, bi elkarrizketen arteko harremanak neurtzeko. Kappa koefizienteak ikerketa medikurako gomendagarriak diren korrelazio-neurriak badira ere (Kraemer 2002)[4], fidagarritasun-itxaropenek ez lukete oso altuak izan beharko, DSM-5eko nortasun-nahasteen formulazioan ez direlako kappa koefiziente oso altuak espero. 0,8 baino altuagoa den kappa ateratzea oso zaila izango litzateke, $0,6-0,8$ artekoa oso egokia izango litzateke eta $0,4-$ 0,6 artekoa onargarria izango litzateke (Kraemer H. et al. 2012) [5].

Bestalde, Wilcoxon-en bi aldetako frogak egin ziren ezaugarri eta eremuekin, bi laginen banaketak berdinak ziren ala ez egiaztatzeko. Bi laginen banaketak antzekoak badira, bi elkarrizketetan antzeko moduan erantzun dutela esan nahi du.

\section{EMAITZAK}

\subsection{Laginaren datu soziodemografikoak}

2. taula. Datu soziodemografikoak.

\begin{tabular}{c|lc}
\hline \multicolumn{2}{c}{ Aldagai soziodemografikoak } & \\
\hline \multirow{2}{*}{ Sexua } & EMAKUMEAK & $\% 40,6$ \\
& GIZONEZKOAK & $\% 59,4$ \\
\hline \multirow{2}{*}{ Adina } & 30 baino gehiago & $\% 71,9$ \\
& 30 edo gutxiago & $\% 28,1$ \\
\hline \multirow{2}{*}{ Egoera zibila } & Ezkongabea & $\% 71,9$ \\
& Ezkondua & $\% 15,6$ \\
& Banandua/dibortziatua & $\% 12,5$ \\
\hline \multirow{2}{*}{ Seme-alabak } & Bai & $\% 21,9$ \\
& Ez & $\% 78,1$ \\
\hline \multirow{2}{*}{ Elkarbizitze mota } & Bakarrik & $\% 18,8$ \\
& Elkarbizitzan & $\% 81,2$ \\
\hline \multirow{2}{*}{ Maila } & Altua & $\% 6,2$ \\
& Ertaina & $\% 71,9$ \\
& Baxua & $\% 21,9$ \\
\hline \multirow{2}{*}{ Inasketa maila } & Lehenengo hezkuntza edo oinarrizko batxillerra & $\% 65,6$ \\
& Heziketa profesionala edo unibertsitate ikasketak & $\% 34,4$ \\
\hline \multirow{2}{*}{ Lan-egoera } & Bai & $\% 28,1$ \\
& Ezomikoa legalak & $\% 71,9$ \\
\hline & Lanean & $\% 50,0$ \\
\hline \multirow{2}{*}{ Ikaslea } & $\% 12,5$ \\
\hline
\end{tabular}




\subsection{Nortasun-nahasteak neurtzeko tresnak}

Lehenengo eta bigarren elkarrizketan nortasun-nahaste moten arteko akordioa kalkulatzeko, hau da, bi alditan pazienteek antzeko puntuazioak izan zituztela kalkulatzeko, kappa koefizienteak kalkulatu ziren.

Nortasun-nahaste antisozialengan lehenengo eta bigarren elkarrizketen arteko kappa koefizienteak 0,8 emaitza izan zuen, eta horrek akordio ona, ia perfektua adierazten du, hau da, subjektuen puntuazioak ia berdinak izan direla adierazten du. Nortasun-nahaste saiheskorraren kasuan, bi elkarrizketen arteko kappa koefizientea 0,6 izan zen, eta horrek bi elkarrizketen arteko akordio ona erakusten du. Nortasun-nahaste bordelinean bi elkarrizketen arteko kappa koefizientea 0,5 izan zen, eta horrek bi elkarrizketen arteko akordio moderatua dagoela adierazten du. Obsesibo-konpultsiboan bi elkarrizketen arteko kappa koefizientea 0,3koa izan zen; akordio baxua adierazten du horrek. Nortasun-nahaste eskizotipikoaren kasuan, Kappa koefizienteari dagokionez, 0 puntuazioa eman zuen, profil horretako pazienterik ez baitzen agertu.

3. taula. Kappa balioak

\begin{tabular}{lc}
\hline \multicolumn{1}{c}{ Nortasun-nahaste motak } & Kappa balioak \\
\hline Antisoziala & 0,8 \\
Saiheskorra & 0,6 \\
Borderline & 0,5 \\
Obsesibo konpultsiboa & 0,3 \\
Eskizotipikoa & 0 \\
\hline
\end{tabular}

Ondorengo grafikoetan [1. irudia], lehenengo eta bigarren elkarrizketetan nortasun-nahaste mota bakoitzean pazienteek izan dituzten balorazioak agertzen dira.

Bi elkarrizketen ezaugarri eta eremuen puntuazioak neurtzeko, Wilcoxonen probak egin ziren. Bi elkarrizketen emaitzen banaketak konparatu ziren proba horien bidez. Kasu guztietan, hipotesi nuluan lehenengo eta bigarren elkarrizketako laginen banaketa berdina dela baieztatzen da.

Kasu guztietan, kalkulaturiko $\mathrm{p}$ balioa alfa $=0,05$ esanguratsutasun maila baino altuagoa denez, ezin daiteke hipotesi nulua baztertu.

Beraz, emaitzek erakutsi zutenez, bi elkarrizketetako puntuazioen banaketa berdina izan zen bi aldietan, hau da, lehenengo eta bigarren elkarrizketako puntuazioak oso antzekoak izan ziren. 

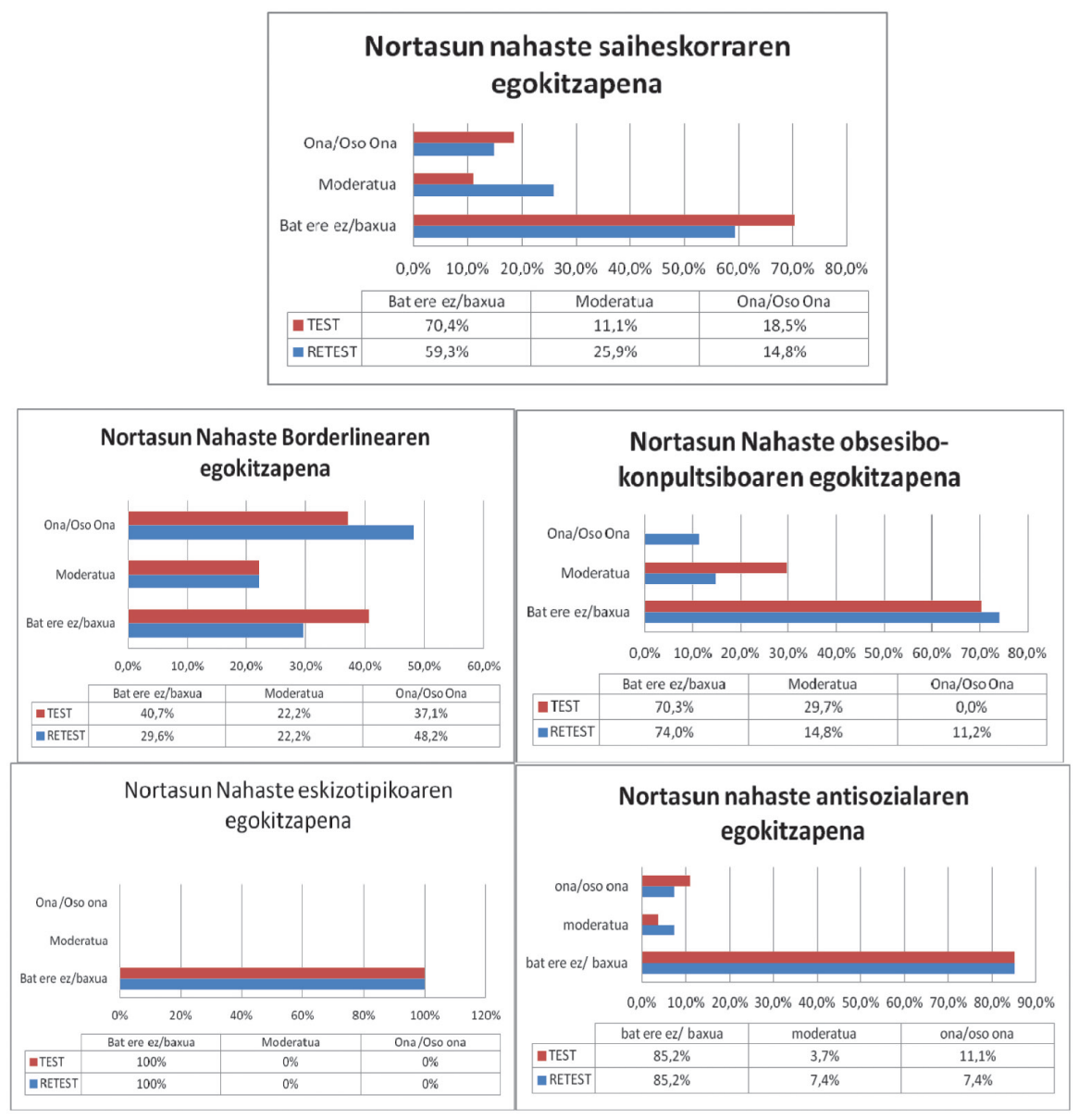

1. irudia. Pazienteen balorazioak bost nortasun-nahaste motetan. Lehenengo eta bigarren elkarrizketak.

4. taula. Wilkoxon froga bilaterala.

\begin{tabular}{lcc}
\hline \multicolumn{1}{c}{ Nortasun eremuak } & p-balioak & Alfa \\
\hline Aurkakotasuna & 0,041 & 0,05 \\
Desinhibizioa & 0,790 & 0,05 \\
Emozio negatiboak & 0,565 & 0,05 \\
Barnerakoitasuna & 0,267 & 0,05 \\
Eskizotipia & 1,000 & 0,05 \\
Konpultsibitatea & 0,299 & 0,05 \\
\hline
\end{tabular}




\section{EZTABAIDA}

Ikerketa honetan euskarara itzuli dira jatorriz ingelesez zeuden tresnak, back translation metodologiaren bitartez. Itzulpen metodologia honen bitartez, euskarara itzulitako DSM-5eko tresnek jatorrizkoen esanahi berdina dutela baiezta dezakegu. Ikerketa honetan aztertu denez, tresna berri hauek guztiz ulergarriak eta erabiltzen errazak dira, bai ebaluatzaile trebatuentzat, bai gaixoentzat ere, ez baita inolako zailtasunik azaldu tresna horiek ulertzeko eta erabiltzeko orduan.

Kappa balioak aztertzen baditugu, ondoriozta dezakegu bost nortasun-nahaste motek ez dituztela nortasun-nahasteak modu guztiz egokian neurtzen. Hirugarren taula aztertzen badugu, nortasun-nahaste saiheskor, antisozial eta borderlinearen kappa koefizienteak onargarriak badira ere nortasun-nahaste obsesibo-konpultsibo eta eskizotipikoak neurtzerakoan, kappa koefizienteak nahiko baxuak dira. Badirudi DSM-5eko nortasunnahaste lan-taldea ere ondorio horretara heldu zela, eta horregatik, DSM5eko nortasun-nahasteen zirriborro berrian (2011ko ekainean sortutakoa), nortasun-nahaste nartzisista eta ezaugarri espezifikoak dituen nortasunnahastea gehitu zituzten. Gaur egun, zirriborro horretako formulazioaren oso antzekoa agertzen da DSM-5eko hirugarren sailean. Hirugarren sail horretan, ikertzeko bidean dauden sailkapenak agertzen dira, eta DSM-5eko lan-taldeek esan duten bezala, seguruenez, DSM-5aren hurrengo errebisioan agertuko diren nortasun-nahasteen sailkapenak horiek izango dira.

Laugarren taulan ikus daitekeenez, Wilkoxon frogek erakusten dute Nortasun ezaugarrien eremuek eta ezaugarriek argi eta garbi neurtzen dituztela nortasun-ezaugarriak. Ondorioz, nortasun-nahasteen ezaugarriak neurtzeko modu egokia dela uste dugu. DSM-5aren hirugarren sailean, nortasun-nahasteen deskribapenean ere eremuak eta ezaugarriak neurtzeko metodologia hau proposatzen da, eta hurrengo DSM bertsioetarako nortasun-nahasteak diagnostikatzean, ezaugarri eta eremuak modu horretan deskribatzea espero da.

Lanaren mugak ondorengoak izan dira. Hasteko, DSM-5aren garapenean zehar aldaketa asko egon dira, eta gure tresnak lehenengo zirriborroan proposatutakoak izan dira, ezin baikinen egon tresnak uneoro aldatzen. Bestalde, ikerketan parte hartu zuten paziente ugari nahiko larriak ziren, eta haien eboluzioak paziente hauek ikerketatik kanpo geratzea eragin zuen. Azkenik, hurrengo ikerketa baterako, lagin zabalagoa lortzea litzateke gure helburua, nahiz eta zail xamarra den aurkitzea nortasun-nahastea duten pazienteak, gainera hizkuntzaz euskaldunak direnak, eta, noski, ikerketan parte hartzeko prest direnak.

DSM-a aldatuz joan da urteetan zehar, eta aldaketa horiek gero eta segurtasun handiagoa ematen dute pazienteak modu egokian diagnostika- 
tuak izan daitezen, bai eta diagnostikatuak izan ez daitezen, oharkabean, nahasterik ez daukatenek. Hori dela eta, garrantzitsua da landa-ikerketak egitea. Landa-ikerketaren bitartez, tresna horiek askotariko testuinguruetan eta askotariko profesionalen jardunean duten portaera ikusten da, eta horrela, tresnen fidagarritasuna handiagotzen da (Kraemer et al. 2010) [6].

Hamarkada bat baino gehiago generaman DSMaren nosologia psikiatrikoaren hobekuntza baten esperoan. 2010eko otsailean DSMaren birkontzeptualizazio orokor bat gauzatu zen, eta nortasun-nahasteena, konkretuki. Aldaketa horren beharra aspaldidanik ikusten zen. Hasteko, nortasun-nahasteak deskribatzeko modua sinpleegia zela esaten zen. Gainera, diagnostiko kategorialen eraginkortasunari buruzko zalantza asko zeuden, eta diagnostikoen arteko komorbilitate asko zegoela esaten zen. Hori guztia dela eta, nortasun-nahasteen lan-taldea buru-belarri ibili da birkontzeptualizazio honetan lan egiten, eta, DSM-5aren lehenengo formulazioa egin zenetik, proposamen eta kritika ugari jaso dituzte DSM-5 eko lan taldeek.

Nortasun-nahasteei dagokienez, DSM-5eko azkenengo bertsioan, hirugarren sailean agertu da nortasun-nahasteen proposamen dimentsionala. Sail horrek, lehen esan bezala, ikerketa gehiago behar ditu oraindik. DSM-5aren sorkuntzaren prozesuan zehar kritika eta zalantza nahiko egon da birkontzeptualizazioaren inguruan, baina, gure esperientziaren arabera, DSM-5aren proposamen berriak erabiltzerakoan ez genuen konplexutasun handirik izan.

\section{ONDORIOAK}

Horregatik, DSM-5eko nortasun-nahasteen ebaluaziorako sorturiko proposamenak aproposak direla ikusi dugu, diagnostikoaren objektibotasunerako, tratamenduaren erabakirako, heterogeneotasuna islatzeko, diagnostikoen arteko gainjartzeak jaisteko, bai eta nortasun-nahasteei buruzko informazio sakonagoa emateko.

\section{ESKER ONAK}

Ikerketan parte hartu duten pazienteei eta laguntza eskaini duten profesional guztiei.

Euskara errektoreordetzari. Euskarazko tesiak egiteko diru-laguntzagatik. 


\section{BIBLIOGRAFIA}

[1] SKODOL, A.E., BENDER, D.S., MOREY, L.C., CLARK, L.A., OLDHAM, J.M., ALARCON, R.D., KRUEGER, R.F., VERHEUL, R., BELL, C.C. eta SIEVER, L.J. 2011 «Personality disorder types proposed for DSM-5». Journal of Personality Disorders, 25, 36-169.

[2] MORAN, M. 2011. «DSM-5 Developers Propose New System for Diagnosing Personality Disorders». Psychiatric News. 46 (18), 1-18.

[3] CAMPO-ARIAS, A. eta HERAZO, E. 2010. «Concordancia intra-e interevaluadores». Revista colombiana de psiquiatría.39(2), 424-432.

[4] KRAEMER, H., PERIYAKOIL, V. eta NODA, A. 2002. «Kapppa coefficients in medical research». Statistics in Medicine. 21, 2109-2129.

[5] KRAEMER, H., KUPFER, D., CLARKE, D., NARROW, W. eta REGIEL, D. 2012 «How Reliable Is Enough?» The American Journal of Psychiatry. 169, 13-15.

[6] KRAEMER, H., KUPFER, D., NARROW, W., CLARKE, D. eta REGIER, D. 2010 «Moving Toward DSM-5. 2010. The Field Trials». American Journal of Psychiatry. 167, 1158-1160. 